\title{
Internal-Short-Mitigating Current Collector for Lithium-Ion Battery
}

\author{
Meng Wang, ${ }^{1}$ Anh V. Le, ${ }^{1}$ Daniel J. Noelle, ${ }^{2}$ Yang Shi, ${ }^{2}$ Y. Shirley Meng, ${ }^{3}$ Yu Qiao ${ }^{1,2 *}$ \\ ${ }^{1}$ Department of Structural Engineering, University of California - San Diego, La Jolla, CA 92093-0085, \\ U.S.A. \\ ${ }^{2}$ Program of Materials Science and Engineering, University of California - San Diego, La Jolla, CA \\ 92093, U.S.A. \\ ${ }^{3}$ Department of Nanoengineering, University of California - San Diego, La Jolla, CA 92093, U.S.A. \\ * Corresponding author. Phone: +1-858-534-3388; Email: yqiao@ucsd.edu
}

\begin{abstract}
Mechanical abuse often causes thermal runaway of lithium-ion battery (LIB). When a LIB cell is impacted, radial cracks can be formed in the current collector, separating the electrode into petals. As separator ruptures, the petals on positive and negative electrodes may contact each other, forming internal short circuit (ISC). In this study, we conducted an experimental investigation on LIB coin cells with current collectors modified by surface notches. Our testing results showed that as the current collector contained appropriate surface notches, the cracking mode of electrode in a damaged LIB cell could be adjusted. Particularly, if a complete circumferential crack was generated, the petals would be cut off, which drastically reduced the area of electrode involved in ISC and the associated heat generation rate. A parameterized study was performed to analysis various surface-notch configurations. We identified an efficient surface-notch design that consistently led to trivial temperature increase of ISC.
\end{abstract}

Keywords: Lithium-ion battery, current collector, mechanical abuse, internal short, thermal runaway

(C) 2017. This manuscript version is made available under the Elsevier user license http://www.elsevier.com/open-access/userlicense/1.0/ 


\section{Introduction}

Lithium-ion battery (LIB) has been extensively studied since its invention [1]. It has superior specific energy and cost-performance balance, compared to traditional lead acid batteries or metal hydride batteries [2]. LIB has broad applications in portable electronic devices, transportation and power systems, etc. In the past couple of decades, much effort was focused on the development of new electrode and electrolyte materials to increase the energy, power, and cycle life of LIB [e.g. 3-6]. Meanwhile, with the significant increase in energy storage capacity and degree of system integration, safety and robustness of LIB cells has become a critical issue [e.g. 7].

A typical LIB cell contains a positive current collector, e.g. an aluminum foil, and a negative current collector, e.g. a copper foil, with active material (AM) layers coated on them. To keep positive and negative electrodes in close proximity while fully separated, there is usually a layer of porous polymer membrane in between, forming an electrode stack. The electrode stack is soaked with electrolyte, based on organic solvents such as ethylene carbonate (EC) and ethyl methyl carbonates (EMC). During normal operation, such a structure is quite efficient and LIB can be well protected by thermal manage systems [8-10]. Upon collision, however, all the external protection mechanisms could fail. The closely packed positive and negative electrodes can be forced into contact, as the thin membrane separator is ruptured. The internal short circuit (ISC) causes uncontrolled discharge [11], resulting in a high peak temperature in a short period of time [12-15]. As a portion of the cell is heated to around $110-130{ }^{\circ} \mathrm{C}$, decomposition of electrolyte and active materials as well as other harmful electrochemical reactions will be triggered. These exothermic reactions would further increase the reaction and heat generation rates, eventually leading to thermal runaway [16-18] and combustion of electrolyte [19].

Traditional internal-short mitigation (ISM) techniques are often activated after the cell temperature exceeds a certain value. Thermally shutdown separators [20-22] and positive thermal coefficient (PTC) materials [23-25] are two examples. They increase the internal impedance of damaged 
LIB cells by limiting the electron or ion transportation. The triggering temperature is usually higher than $120{ }^{\circ} \mathrm{C}$, inefficient when the cell size is large or the cell damage is severe [26].
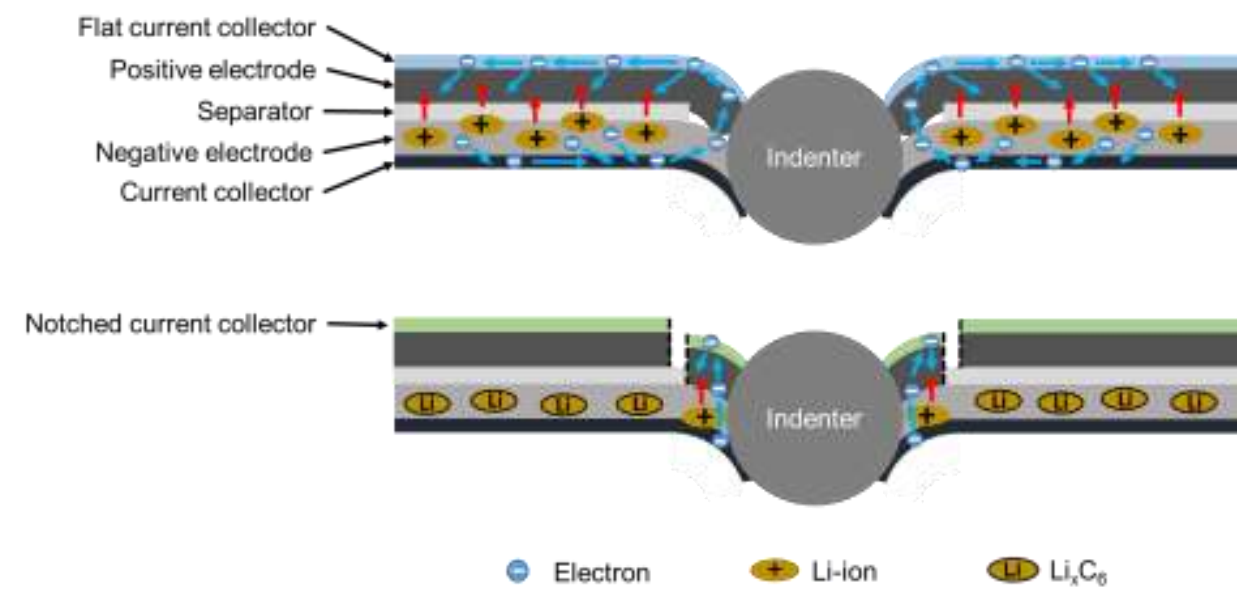

Fig. 1 Comparison of flat current collector (top) and modified current collector (bottom) subjected to indenter impact. The blue arrows in electrode layers indicate transportation of electrons; the red arrows indicate transportation of lithium ions.

We recently investigated mechanically triggered ISM methods. Once a LIB cell is deformed, a mechanically triggered mechanism can react before the temperature starts to rise. Consider the LIB cell as an equivalent circuit model [27]. After ISC is formed, the heat generation rate $(q)$ is governed by the cell resistance $(R)$ and the shorting resistance $(r): q=U^{2} /(R+r)$, where $U$ is the voltage. In the ISC, current flows from the AM layer to the shorting spot, mainly through the current collector. At the shorting spot, current passes through the AM layers. For a LIB coin half-cell, the shorting resistance $(r)$ contains the contributions from the current collector $\left(r_{\mathrm{Al}}\right)$, the lithium metal negative electrode $\left(r_{\mathrm{Li}}\right)$, and the AM layer $\left(r_{\mathrm{am}}\right)$, i.e. $r=r_{\mathrm{Al}}+r_{\mathrm{Li}}+r_{\mathrm{am}}$. Our experimental results [28-31] showed that increasing only the shorting resistance of AM layer was insufficient to mitigate heat generation of ISC. For instance, with the addition of damage homogenizers (DH) in AM, the peak temperature increase of damaged LIB cells was not significantly reduced. 
In the current research, we investigate a method to increase the resistance of current collector, $r_{\mathrm{Al}}$, by controlling its fracture mode. In general, the deformability of current collector $(\sim 2 \%)$ is much smaller than that of membrane separator (70-150\%) [32]. Hence, as the LIB cell deforms, current collector tends to fail earlier. We aim to entirely disconnect the shorting spot from the major part of electrode (Fig.1), so that only a relatively small area of electrode is involved in the ISC.

Fracture of electrode is dominated by cracking of current collector, because the mechanical strength of current collector is higher than that of AM layer by nearly two orders of magnitude [33]. Upon dynamic loading, a metal thin film often undergoes petaling. That is, as radial cracks are generated from the impact location, the sectors in between are separated as petals. The petals of positive and negative electrodes can be compressed to contact each other, forming an ISC wherein the current collectors offer the most conductive path. It is envisioned that by creating appropriate surface notches in current collector, circumferential cracking can be promoted and it would help isolate the petals from the shorting spot. Hence, the shorting resistance may be drastically increased.

\section{Experimental}

Aluminum current collectors were modified through photolithography, as depicted in Fig.2a. The initial current collector thickness was $\sim 18 \mu \mathrm{m}$. The current collector was cut into $70 \mathrm{~mm}$ by $70 \mathrm{~mm}$ square pieces and repeatedly rinsed with deionized water and acetone. After dehydration at $150{ }^{\circ} \mathrm{C}$ on a hotplate (Thermo Scientific, HP131535Q) for $20 \mathrm{~min}$, the square aluminum piece was attached to a flat glass substrate (McMaster, 8476K13) with a layer of isopropyl alcohol (IPA) applied at the interface (Fig.2b). Excessive IPA was removed by Kimwipes. The glass substrate was affixed onto a spin coater, and photoresist (TRANSENE, KLT 6008) was spin-coated on the current collector. The spin coater was accelerated at $400 \mathrm{rpm} \cdot \mathrm{s}^{-1}$ to $4000 \mathrm{rpm}$, and maintained at $4000 \mathrm{rpm}$ for $60 \mathrm{sec}$. After coating, the aluminum film was peeled off from the glass substrate and soft-baked at $60{ }^{\circ} \mathrm{C}$ for $15 \mathrm{~min}$ to fully solidify the photoresist. A photomask, provided by Fineline-Image, was firmly compressed onto the coated 
aluminum film by a 6.4 - $\mathrm{mm}$-thick glass slide, and exposed to a $0.3 \mathrm{~mW} \cdot \mathrm{cm}^{-2}$ parallel UV light source for $180 \mathrm{sec}$. Then, the aluminum film was attached onto a clean glass substrate (McMaster, 7648A32), and its edges were sealed by Kapton tapes (McMaster, 7648A32). The photoresist was developed by immersing the glass-aluminum bilayer in tetramethylammonium hydroxide aqueous solution (TMAH, TRANSENE) for $30 \mathrm{sec}$, followed by drying on hotplate at $80{ }^{\circ} \mathrm{C}$ for $2 \mathrm{~min}$. The average thickness of solidified photoresist was $\sim 9 \mu \mathrm{m}$ and the line width was $\sim 11 \mu \mathrm{m}$, measured by a ZYGO NewView Surface Profiler. Next, the glass-aluminum bilayer was placed in a 150-mm-diameter dish and etched in $150 \mathrm{~mL}$ Type-A Transene Aluminum Etchant at $\sim 53{ }^{\circ} \mathrm{C}$ for $18 \mathrm{~min}$. After etching, the residual photoresist was stripped from the aluminum film by dipping it in acetone for $30 \mathrm{sec}$. Six different surface-notch designs were investigated, as shown in Fig. 2c. For all the current collectors, the depth and the width of surface notches were $9 \pm 1 \mu \mathrm{m}$ and around $25 \mu \mathrm{m}$, respectively, measured by a ZYGO NewView Surface Profiler.

Table 1. Processing parameters of positive electrodes

\begin{tabular}{lll}
\hline & Type 1 & Type 2 \\
\hline NCM:PVDF:CB mass ratio & $93: 4: 3$ & $80: 10: 10$ \\
Powder-to-NMP ratio $(\mathrm{g}: \mathrm{mL})$ & $1: 0.4$ & $1: 1$ \\
Initial AM coating thickness $(\mu \mathrm{m})$ & $\sim 200$ & $\sim 200$ \\
Final AM layer thickness after calendering $(\mu \mathrm{m})$ & 62 & 36 \\
AM loading $\left(\mathrm{mg} / \mathrm{cm}^{2}\right)$ & 17.44 & 8.19 \\
Composite electrode density $\left(\mathrm{g} / \mathrm{cm}^{3}\right)$ & 2.81 & 2.28 \\
\hline
\end{tabular}

Positive electrode was processed by mixing NCM523 powders (Toda America, NCM-04ST) with polyvinylidene fluoride binder (PVDF) (Sigma-Aldrich, Product No. 82702) and nano-scale conductive filler carbon black (CB) (Timcal, C-nergy Super-C65). The mixed powders were homogenized in 1Methyl-2-pyrrolidinone (NMP) (Sigma-Aldrich, Product No. 494496), using a sonicator (Qsonica, Model 
No. Q55) at 70\% power for 10 minutes. The slurry was coated on the modified current collector using an electrode coater (MTI, EQ-Se-KTQ-100) and dried in a VWR vacuum oven at $80{ }^{\circ} \mathrm{C}$ for $24 \mathrm{~h}$. The dried electrode was densified using a roller press (Durston DRM F150). Two types of positive electrodes of different compositions were prepared (Table 1). Reference positive electrode was made by coating the AM slurry on flat current collector. For modified positive electrode, two groups of samples were produced, with the slurry coated on either the patterned or the un-patterned side of current collector (Figs.2d and 2e).

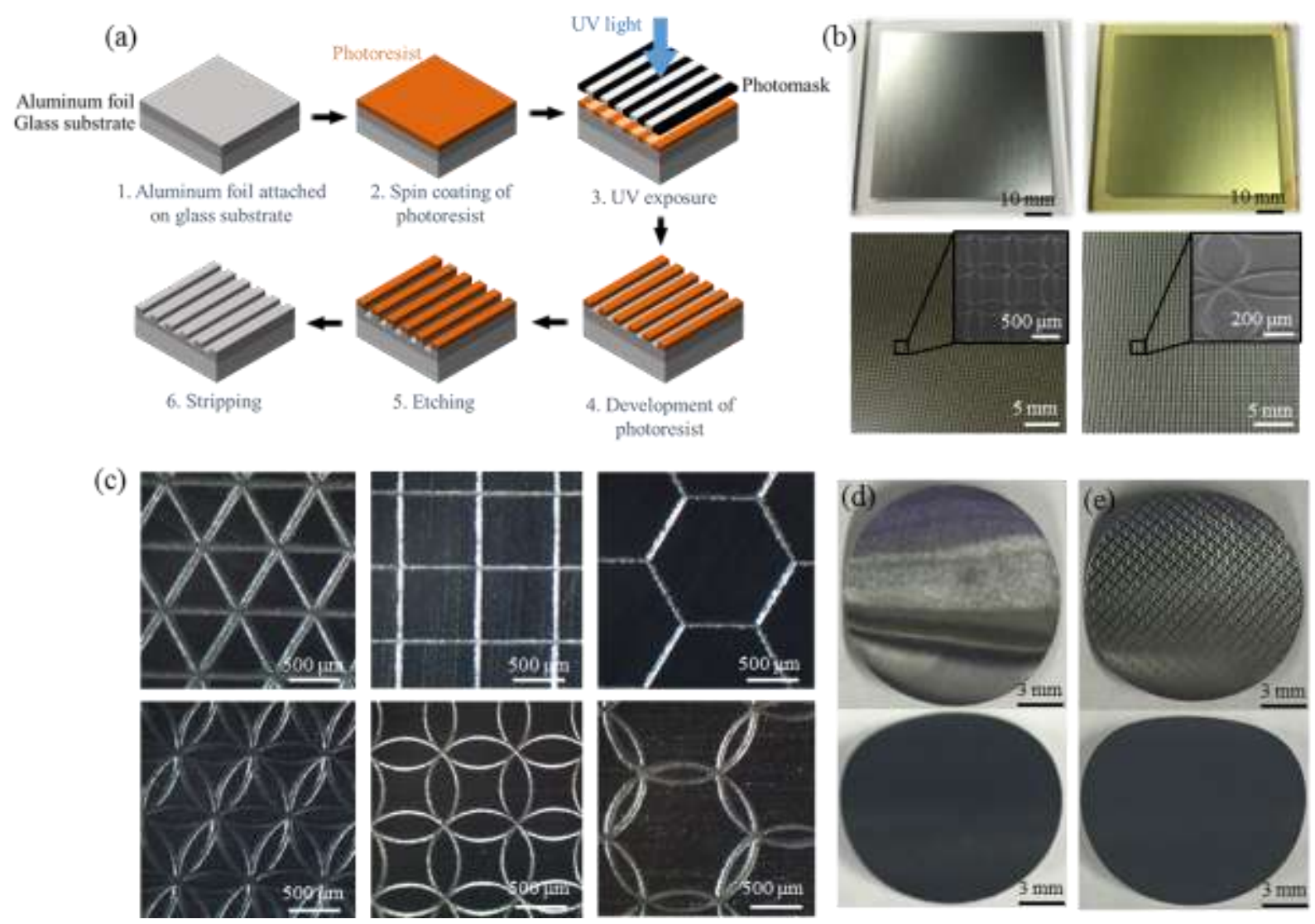

Fig. 2 (a) Schematic of processing procedure of modified current collector. (b) Current collector attached on glass substrate (top-left); current collector with the photoresist coating (top-right); photomask (bottomleft); finished current collector (bottom-right). (c) Modified current collectors with different surface-notch

designs: triangular unit with straight edges (top-left), square unit with straight edges (top-middle), hexagonal unit with straight edges (top-right), triangular unit with double-curved edges (bottom-left), square unit with double-curved edges (bottom-middle), and hexagonal unit with double-curved edges (bottom-right). Top and bottom views of positive electrode after calendaring, with the AM layer coated on (d) the notched side or (e) the flat side of current collector. 
The positive electrode was cut into 14.3-mm-diameter circular pieces using a hammer driven punch (McMaster, 3427A16). In an MBraun Glove Box $\left(\mathrm{H}_{2} \mathrm{O}<0.5 \mathrm{ppm}\right)$, the positive electrode was assembled into Model-2016 coin cells, with lithium (Li) discs as negative electrodes. Reference cells were assembled with reference positive electrodes, and modified cells were assembled with modified positive electrodes. The size of the lithium disc was $15.4 \mathrm{~mm}$ in diameter and $1.1 \mathrm{~mm}$ in thickness. In each cell, a 7.95-mm-radius 20- $\mu$ m-thick PP/PE/PP separator (Celgard 2320) was sandwiched by the positive and negative electrodes. The assembled electrode stack was placed in the bottom cell case. About $30 \mu \mathrm{L}$ BASF electrolyte (1M LiPF 6 in 1:1 EC-EMC) was added, immediately before the top cell case was sealed using a crimper (MTI MSK-110) with the operational pressure of $5 \mathrm{MPa}$. The assembled LIB cells were rested at ambient for 12 hours to ensure the full wetting of AM layer with electrolyte.

For impact testing, the LIB coin cells were charged to $4.6 \mathrm{~V}$ at $0.1 \mathrm{C}$ by an MTI BST8-3 Battery Analyzer. After charging, the cells were disassembled in the glove box. The top cell case was modified by a 6.4-mm-diameter hole at the center. The cell was then re-assembled, with an additional 150 - $\mu$ m-thick polyethylene (PE) film between the aluminum current collector and the modified top cell case. As suggested by the United States Advanced Battery Consortium (USABC) and the National Aeronautics and Space Administration (NASA) [34,35], the impact loading was intensified by a spherical indenter (McMaster, 9599K12). A 4.8-mm-diameter alumina ball was placed on top of the opening of the modified cell case (Figs.3a, 3b), secured by a 4.8-mm-diameter polyurethane (PU) o-ring (McMaster, 9452K11). The indenter, o-ring, along with a steel rod striker were held in a PU container. The battery cell was hosted in a PU base, which had a 10-mm-diameter through hole at the center.

Impact tests were performed by dropping a $7.8 \mathrm{~kg}$ cylindrical steel hammer onto the indenter, with the drop distance of $50 \mathrm{~mm}$. The input kinetic energy was $3.9 \mathrm{~J}$. The temperature profile of the impacted cell was recorded by a Type-K thermocouple connected to an Omega OM-EL-USB-TC temperature recorder. The tip of the thermocouple was attached to the outer cell case, $5 \mathrm{~mm}$ away from 
the center, by using Kapton polyimide tapes (McMaster, 7648A713). The temperature distribution was relatively uniform in the coin cell case, as more than $95 \%$ of the cell mass came from the thermally conductive stainless steel cell case and the lithium disc. Moving the thermocouple tip farther away from the cell center did not have evident influence on the measurement result. For each surface-notch design, ten cells were tested.
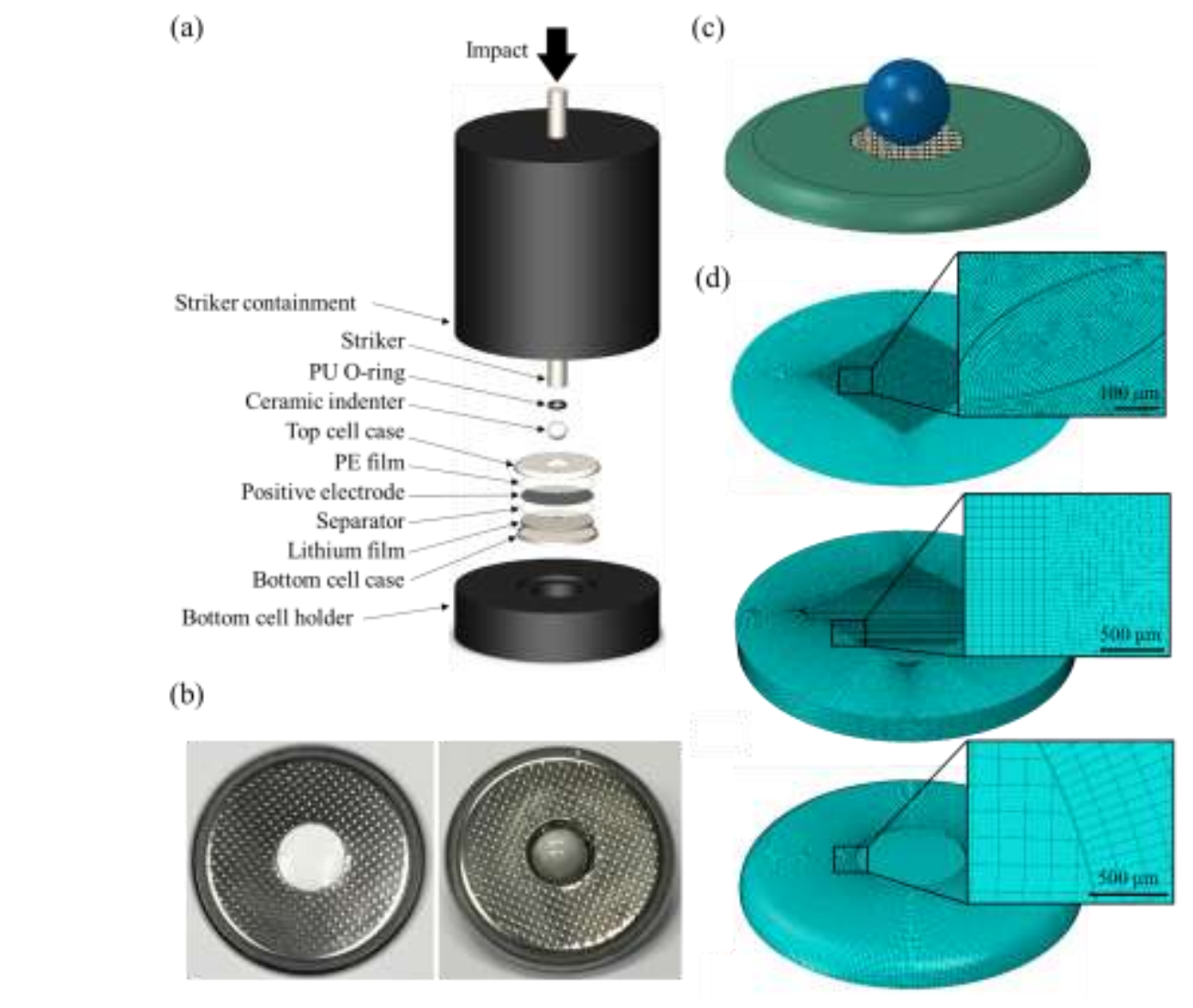

Fig.3. (a) Impact experimental setup. (b) Coin cells before (left) and after (right) the impact test. (c) Finite element model of coin cell. (d) Meshing of current collector (top), lithium disc (middle), and cell case (bottom) used in the finite element analysis.

\section{Computer Simulation}

Finite element analysis (FEA) were conduct using ABAQUS Explicit. The coin cell was modeled with the same geometry and materials as the testing sample, as shown in Fig.3c. The ceramic indenter was modeled as a rigid sphere, with the diameter of $4.8 \mathrm{~mm}$. The load was applied on the indenter by a 
rigid plate with the mass of $7.8 \mathrm{~kg}$ and the initial velocity of $1 \mathrm{~m} \cdot \mathrm{s}^{-1}$ normal to cell surface. The coin cell model contained an aluminum current collector, a lithium disc, and a steel cell case. The AM layer and the membrane separator were ignored, since they contributed little to the electrode stiffness and strength [32,36]. The diameter and thickness of cell case were $20 \mathrm{~mm}$ and $1.59 \mathrm{~mm}$, respectively. The wall thickness of coin cell case was $0.22 \mathrm{~mm}$. The top cell case had an edge curvature of $1.15 \mathrm{~mm}$. The current collector was $14.3 \mathrm{~mm}$ in diameter and $18 \mu \mathrm{m}$ in thickness. The lithium disk had the thickness of $1.1 \mathrm{~mm}$ and the diameter of $15.6 \mathrm{~mm}$. The surface notches in current collector were modeled as rectangular grooves with the depth of $9 \mu \mathrm{m}$ and the width of $25 \mu \mathrm{m}$. Boundary condition was applied on a ring area at the cell bottom, with all degrees of freedom being fixed between diameters of $12.5 \mathrm{~mm}$ and $20 \mathrm{~mm}$.

Table 2. Material properties of the finite element model

\begin{tabular}{|c|c|c|c|}
\hline & Current Collector & Lithium disc & Cell case \\
\hline Material & Aluminum 1235 H18 & Lithium & Stainless steel 304 \\
\hline Young's Modulus (GPa) & 69 & 7.8 & 197 \\
\hline Poisson's Ratio & 0.33 & 0.36 & 0.29 \\
\hline Yield Stress (MPa) & 151.7 & 0.85 & 215 \\
\hline Ultimate strength (MPa) & 165.5 & 1.38 & 6.4 \\
\hline Failure strain (\%) & 2 & 6.4 & 70 \\
\hline$\left(\mathrm{g} / \mathrm{cm}^{3}\right)$ & 0.534 & 8.0 & \\
\hline
\end{tabular}

The aluminum film, lithium disc, and cell case were modeled with self-contact. The normal direction was modeled as hard contact. The tangential direction was modeled by using a penalty function with the global friction coefficient of 0.3. Three-dimensional eight-node reduced-integration element (C3D8R) was employed for all the cell components. The mesh sizes of the current collector, the lithium 
disc, and the cell case were respectively $40 \mu \mathrm{m}, 160 \mu \mathrm{m}$ and $160 \mu \mathrm{m}$. For the current collector and lithium disc, the mesh for the central $6 \times 6 \mathrm{~mm}$ region was refined to $10 \mu \mathrm{m}$ and $20 \mu \mathrm{m}$, respectively (Fig.3d).

(a)

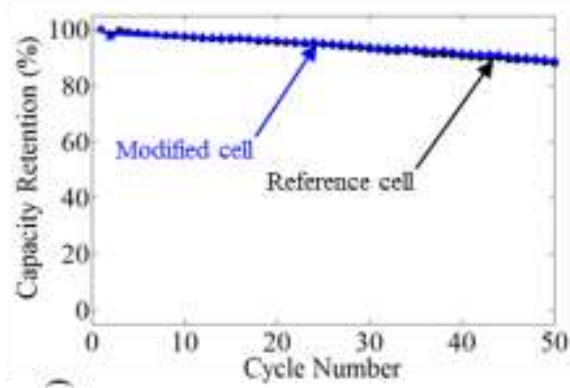

(c)

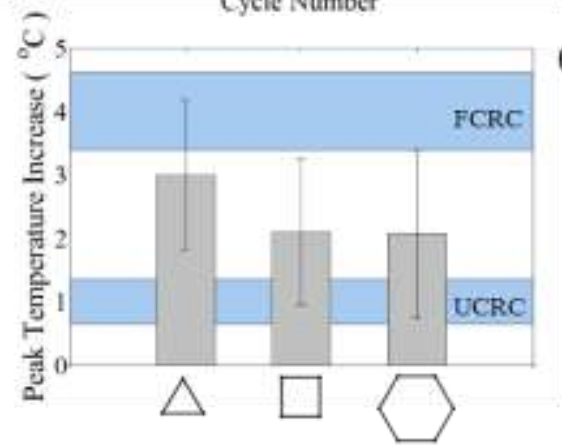

(e)

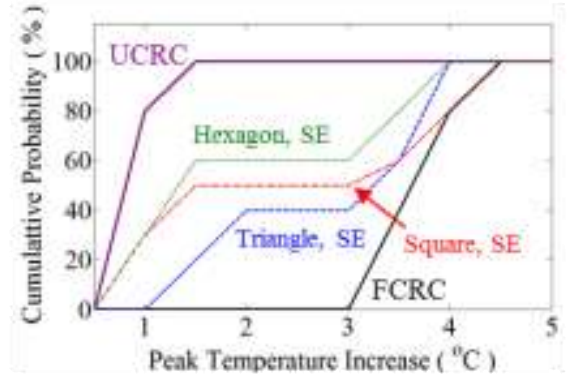

(b)

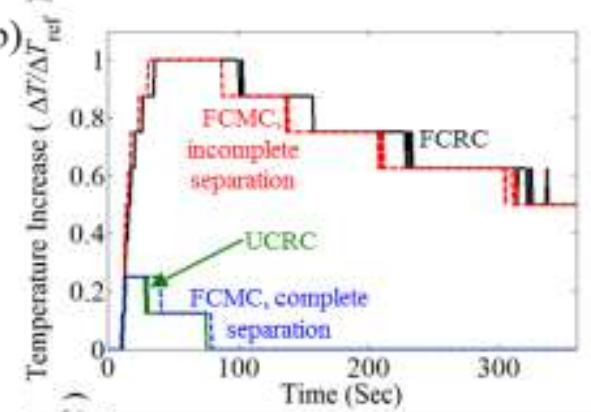

(d)

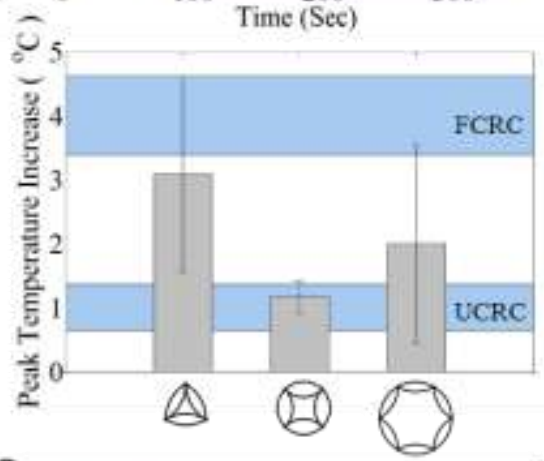

(f)

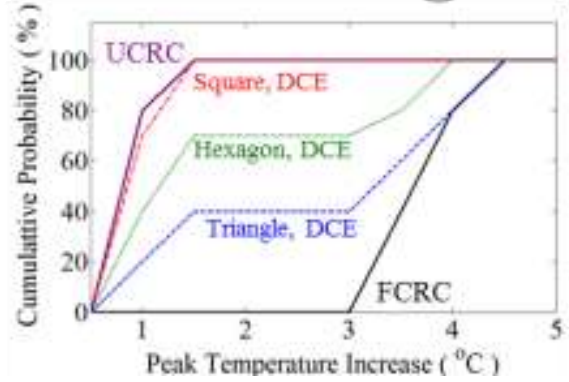

Fig.4. (a) Cycling performance of LIB coin cells with flat current collector and modified current collector. (b) Typical temperature profiles of fully charged reference cell (FCRC), uncharged reference cell (UCRC), and fully charged modified cells (FCMC) with incomplete separation of damaged site or with complete separation of damaged site; $\Delta T_{\text {ref }}$ is the average peak temperature increase of FCRC. Maximum temperature increase $\left(\Delta T_{\max }\right)$ of coin cells based on current collectors modified by surface notches with units of (c) straight edges (SE) and (d) double-curved edges (DCE); the unit shape is shown below each data point; error bars are also given; the blue bands indicate the typical ranges of peak temperature increase of FCRC and UCRC, respectively. Cumulative probability of $\Delta T_{\max }$ of coin cells based on current collectors modified by (e) SE notches and (f) DCE notches; active material layers are coated on the patterned side of current collectors.

The material properties are shown in Table 2 [37-39]. Linear elastic-plastic models were used for all cell components. Damage model was defined for the aluminum to predict crack formation and 
propagation. Ductile damage criteria were employed and the damage initiation was based on failure strain. Since the impact velocity was relatively low, the fracture strain was assumed independent of the strain rate. The fracture strain was set to $2 \%$ at a stress triaxiality of 0 and 0.3 . To avoid compressive damage, the compressive fracture strain was set to $1000 \%$ at a stress triaxiality of -0.3 [40]. Materials degradation was not considered. Element removal was enabled when the residual stiffness of an element was less than $1 \%$ of the initial stiffness.
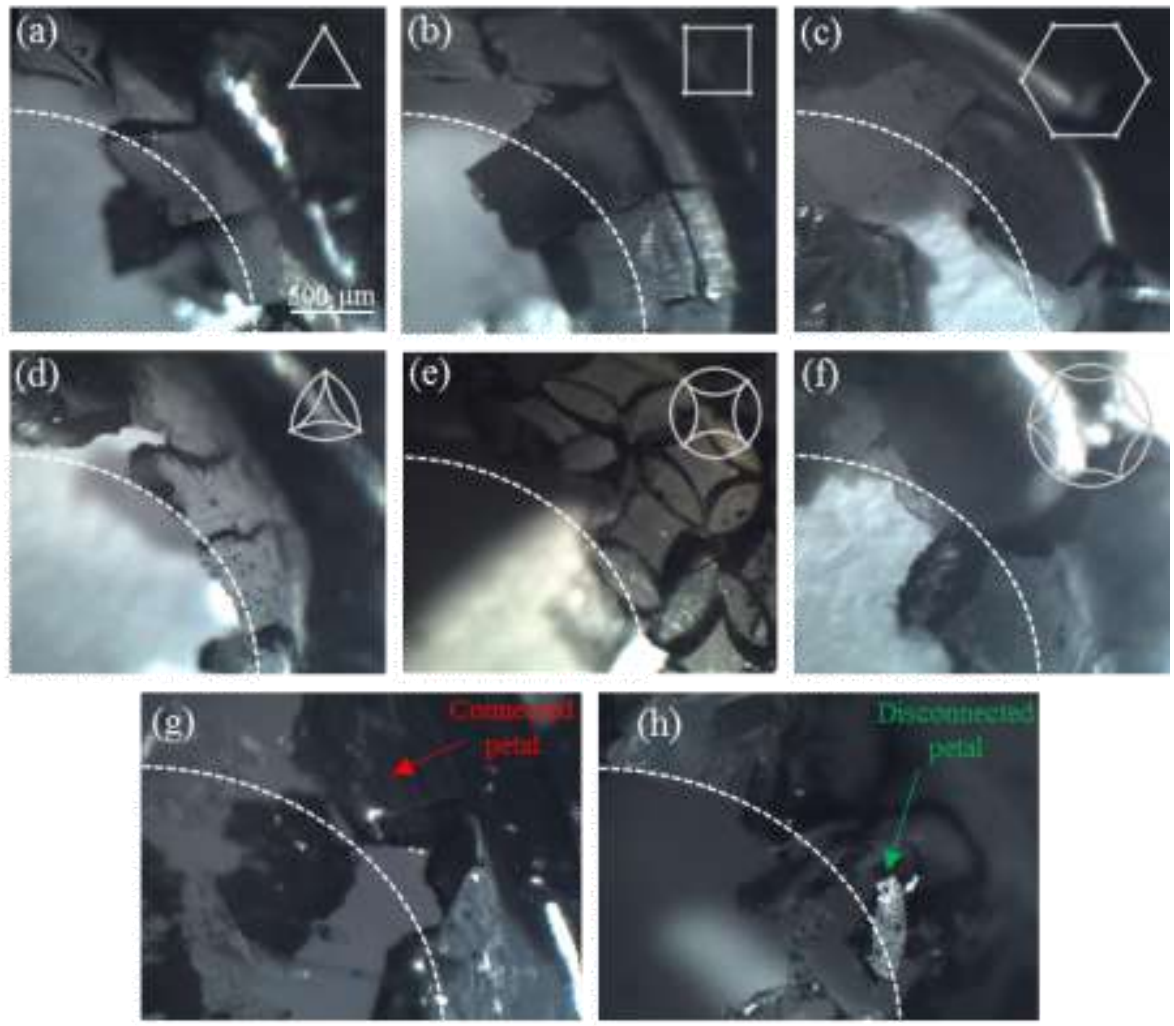

Fig.5. Typical cracking modes of current collectors with various surface-notch designs: (a) triangular unit with straight edges; (b) square unit with straight edges; (c) hexagonal unit with straight edges; (d) triangular unit with double-curved edges; (e) square unit with double-curved edges; and (f) hexagonal unit with double-curved edges. Bottom view of impacted current collector and separator with two representative surface-notch designs: (g) hexagon unit with straight edges and $(\mathrm{h})$ circular unit with double-curved edges. The dashed lines show the boundary of indenter. The scale is the same for all the photos. The active material is coated on the patterned side of current collector.

\section{Discussion}


Figure 4a demonstrates the similar cycling performance of the reference cell with flat current collector and the cell with modified current collector. The LIB cells are charged and discharged between 4.3 $\mathrm{V}$ and $3.0 \mathrm{~V}$ at $1 \mathrm{C}$ for 50 cycles. The reference and the modified cells have similar initial capacity around $148 \mathrm{mAh} / \mathrm{g}$ and similar capacity retention. That is, the modification of the geometry of current collector does not affect the electrochemical reactions.

Figure $4 \mathbf{b}$ shows the temperature profiles of reference and modified LIB cells in impact tests. For the fully charged reference cell, the temperature increase is mainly caused by the Ohmic heating of ISC. For the uncharged reference cell, the temperature increase is due to the plastic deformation and friction of cell components, only $\sim 25 \%$ of that of charged reference cell. For the modified cells, there are two typical temperature profiles: When positive and negative electrodes are in contact, the peak temperature increase $\left(\Delta T_{\max }\right)$ tends to be similar to that of fully charged reference cell; when the contact between positive and negative electrodes is avoided, $\Delta T_{\max }$ is similar to that of uncharged reference cell.

The heat generation rate of ISC may be expressed as $q=U^{2} /(R+r)$ [27]. For a coin half-cell, $R$ is typically larger than $100 \Omega$ [41]. The shorting resistance $r=r_{\mathrm{Al}}+r_{\mathrm{Li}}+r_{\mathrm{ce}}$. Usually, $r$ is governed by the resistance of composite electrode layer $\left(r_{\mathrm{ce}}\right)$, which is much higher than $r_{\mathrm{Al}}$ and $r_{\mathrm{Li}}$ [42]. The value of $r_{\mathrm{ce}}$, for an order-of-magnitude assessment, can be calculated as $r_{\text {ce }}=\rho d / A$, where $\rho \sim 10 \Omega \cdot \mathrm{mm}$ [42] is the resistivity of AM layer, $d \sim 0.06 \mathrm{~mm}$ is the thickness of electrode, and the contact area $(A)$ is $\sim 1 \mathrm{~mm}^{2}$. Thus, the shorting resistance $(r)$ is $\sim 0.6 \Omega$, lower than the cell resistance $(R)$ by more than two orders of magnitude, and it has little influence on $\Delta T_{\max }$. If the contact area $(A)$ is drastically decreased, $r$ would be much larger and $\Delta T_{\max }$ would be much lower.

Compared to the reference cell, LIB cells based on current collectors with triangular or hexagonal surface-notch patterns have somewhat lower average peak temperatures in the impact tests, as shown in Figs. 4c and 4d. The relatively large data scatter is associated with the bimodal distribution of peak temperature, which can also be observed from the cumulative probability curves (Figs. 4e and $4 \mathbf{f}$ ). The cumulative probability is defined as the probability that $\Delta T_{\max }$ is lower than or equal to a certain value $(T)$, 
i.e. $F\left(\Delta T_{\max }\right)=P\left(\Delta T_{\max } \leq T\right)$, where $F$ is the cumulative probability function. In these cells, it is observed that circumferential cracks are only partially formed, resulting in incomplete disconnection of petals (Figs. 5a-5f). After impact, if the connected petals are covered by ruptured separator, the heat generation would be largely reduced; if there is any random mismatch between separator and connected petals (Fig. 5g), contact between positive and negative electrodes would lead to severe heat generation. The randomness of fracture modes of both current collector and separator renders the two surface-notch designs inefficient for ISC mitigation. Square unit with double-curved edges is the most efficient configuration. It has the lowest average peak temperature and the smallest data scatter.
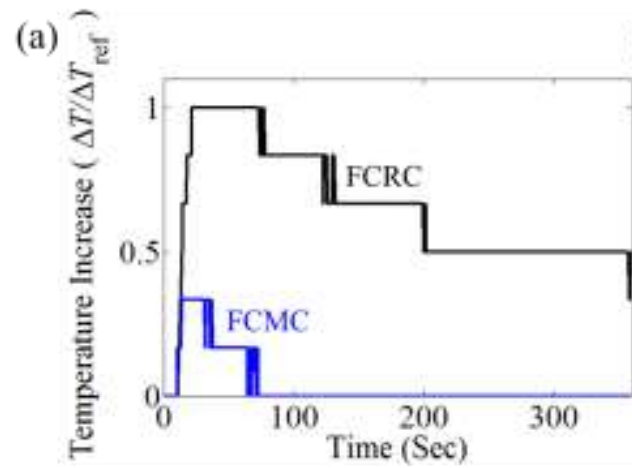

(b)

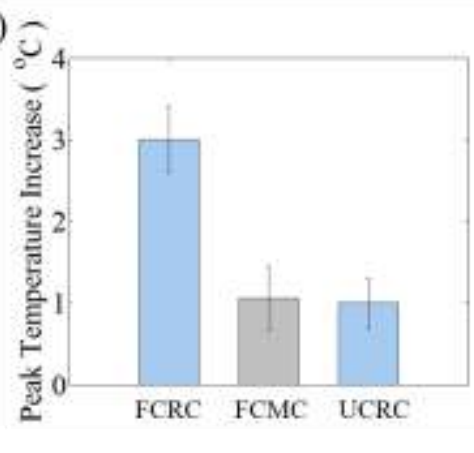

(c)

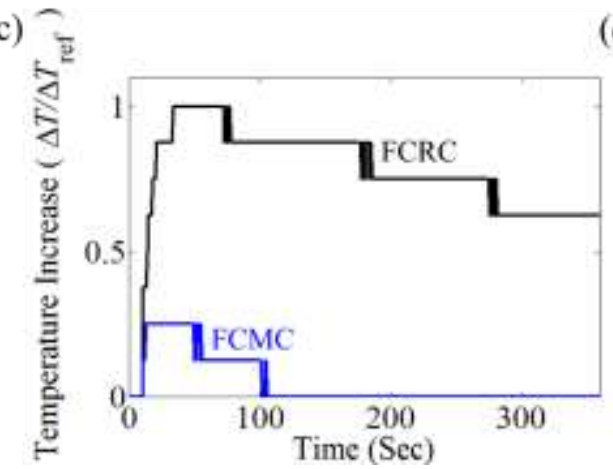

(d)

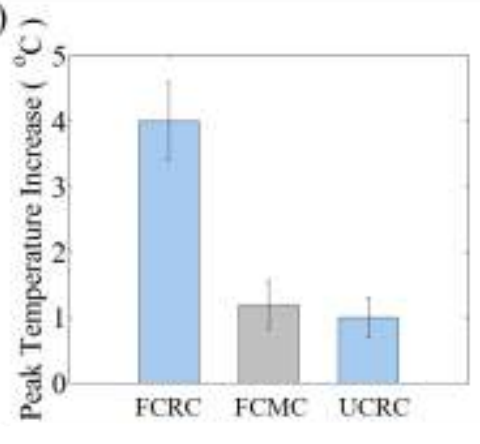

Fig.6. Impact testing results of LIB cells with the NCM:CB:PVDF mass ratio of 80:10:10: (a) Typical normalized temperature profiles and (b) maximum temperature increase $\left(\Delta T_{\max }\right)$ of fully charged reference cells (FCRC), fully charged modified cells (FCMC), and uncharged reference cells (UCRC); the active material layer is coated on the patterned side of current collector; $\Delta T_{\text {ref }}$ is the average temperature increase of FCRC. Impact testing results of cells with the AM layers coated on the flat side of modified current collectors: (c) Typical normalized temperature profiles and (d) $\Delta T_{\max }$.

The cracking mode of modified current collector is sensitive to the geometry of surface notches. The notch patterns with triangular and hexagon units tend to promote the formation of radial cracks, while 
the square units with double-curved edges promote circumferential cracking. In the former mode, radial cracks are generated from the point of impact, and advance along the radial directions. Typically, there are 6-8 radial cracks in each sample. In between two radial cracks, the current collector petals are well connected to the far field. The petals are bent downward by the indenter and penetrate through the membrane separator (Fig. 5g), forming a conductive path between positive and negative electrodes. In the latter mode, circumferential cracks completely cut off the petals, so that the damaged area is isolated from the undamaged electrode (Figs. 5e and 5h) and the shorting resistance ( $r$ ) becomes much larger. That is, the circumferential cracks disable the ISC current in the large undamaged portion of electrode. Only a relatively small region immediately adjacent to the shorting spot, $\sim 10 \%$ of the total electrode area, contributes to the heat generation. The overall ISC current is reduced proportionally by $\sim 10$ times.

The effectiveness of the modified current collector is further verified by using a different AM with the NCM:CB:PVDF mass ratio of 80:10:10. As shown in Figs. 6a and $6 \mathbf{b}$, the peak temperature increase of the modified cells is reduced to the same level as uncharged reference cell, suggesting that the working mechanism of modified current collector is independent of the carbon content in AM. The internal shorting behavior of LIB is largely determined by the cracking mode of current collector.

Figures $6 \mathbf{c}$ and $\mathbf{6 d}$ show the impact testing results of LIB cells with the AM layers coated on the flat side of modified current collectors; the surface notches have square units and double-curved edges. These cells exhibit similar behaviors, compared to those with AM coated on the modified side of current collectors. It suggests that the side of AM coating is not a vital factor, which can be attributed to that the fracture mode of current collector is not affected by the direction of impact. Under penetration, a thin metal film usually undergoes mode-I fracture $[43,44]$. Since the mechanical strength of the AM layer is much lower than that of the current collector [32], the tensile stresses generated by the indenter are nearly the same from both sides.

Energy release rate can be expressed as $G=K_{\mathrm{I}}^{2} / E$ [45], with $E$ being Young's modulus; for petal formation, the stress intensity factor $K_{\mathrm{I}}=f(n) \cdot \sigma_{\mathrm{t}} \sqrt{\pi a}$ [46]. Hence, $G=f^{2}(n) \cdot \sigma_{\mathrm{t}}^{2} \pi a / E$, where 
$f(n)=2 / \sqrt{n}$ is a function of radial crack density, $n$ [47]; $\sigma_{\mathrm{t}}$ is the equivalent tensile stress; and $a$ is the average crack length. The crack can propagate only when $G$ reaches the critical energy release rate, $G_{\mathrm{c}}$. It can be seen that the cracking mode of current collector is determined by the radial crack density and the local tensile stress. Higher $f(n)$ and $\sigma_{\mathrm{t}}$ lead to a higher energy release rate, promoting circumferential cracking. The radial crack density is closely correlated with the notch density $\rho=\sum_{\bar{\Omega}} L / A$, where $L$ is the unit size of surface notches, around $700 \mu \mathrm{m}$ in the current study; $\bar{\Omega}$ is the domain of indentation and $A$ is its area, $\sim 18 \mathrm{~mm}^{2}$. The notch density associated with the triangular, square, and hexagonal units are 6.6, 2.86 , and $1.65 \mathrm{~mm} \cdot \mathrm{mm}^{-2}$, respectively. With a higher notch density, the number of cracks is larger, prone to petal formation [48]. The trianglar pattern has the densest notches, resulting in the densest radial crack network and the smallest $f(n)$. Therefore, the trianglar pattern is least favorable for ring crack formation and petal separation. The cracking mode of the hexagonal pattern is also dominated by the notch density. Unlike the trianglar pattern, the hexagonal pattern has the lowest notch density and the largest energy release rate. However, the size of the hexagonal unit is around one-third of the indenter size. A number of hexagonal units are only partially deformed (Figs. 4c and 4f), so that circumferential cracking is incomplete.

Note that $\sigma_{\mathrm{t}}$ is also affected by the surface-notch pattern. The square pattern has a moderate notch density, and its cracking mode is govened by the geometry of the notch edges. Figures $\mathbf{4 b}$ and $\mathbf{4 d}$ show that the square unit with double-curved edges consistently leads to the complete formation of circumferential crack ring, because of the large tensile stress perpendicular to the circumferential notches. Denote the reference tensile stress as $\sigma_{0}$. Assume that the indenter induces a circular hole in the center of current collector. At the tip of a radial crack, the local circular stress $\sigma_{\theta}=2 \sigma_{0}$ and the local radial stress is $\sigma_{\mathrm{r}}=0$. In a modified current collector, cracks always form from the surface notches, because of stress concentration. As the radial stress in circumferential notches exceeds the ultimate strength of the material, crack bifurcation would happen. For a modified current collector with square notch units of straight edges [49] 


$$
\sigma_{t}=2 \sigma_{0} \frac{x}{\sqrt{\left(\frac{3}{2} d^{2}\right)}+x^{2}}
$$

If the edges are double-curved [49]

$$
\sigma_{t}=2 \sigma_{0} \sin \left(\sin ^{-1} \frac{\sqrt{2} x}{d} \pm \tan ^{-1} \frac{x}{2 d-\sqrt{\frac{d^{2}}{2}-x^{2}}}\right)
$$

where $d=700 \mu \mathrm{m}$ is the edge length and $x$ is the horizontal coordinate with the origin at the center of the circumferential notch. Figure 7 shows the calculated results of Eqs.1 and 2. The tensile stress perpendicular to circumferential notch of double-curved edges is much higher than that of straight edges.

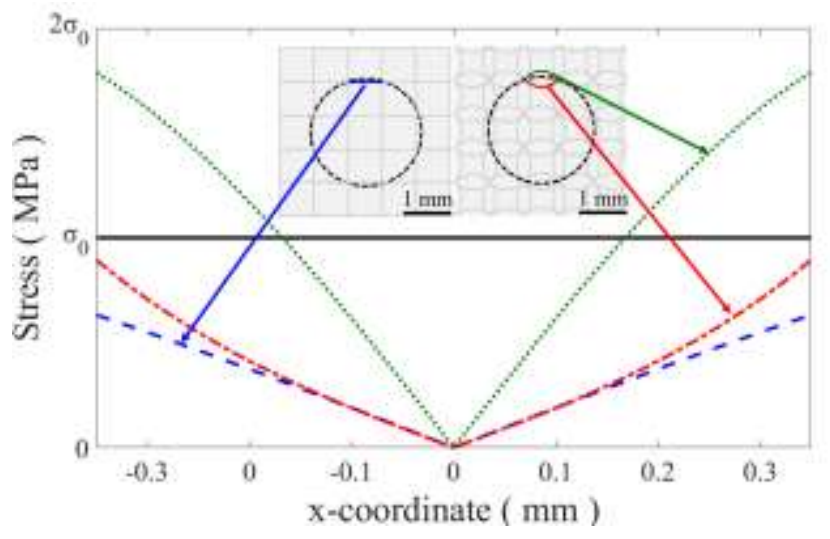

Fig.7. Comparison of maximum tensile stresses along circumferential surface notches of straight edges and double-curved edges. The dashed black circles in the insets indicate the location of crack tips; $\sigma_{0}$ is the reference tensile stress.

The experimental observation is confirmed by the FEA result. Figures 8a and 8b show that flat current collector, upon impact, exhibits typical petaling characteristics: Although a small portion of the current collector may be truncated in the central area, with the propagation of radial cracks the formation of petals is inevitable. The petals are bent downward by the indenter, leading to the direct contact between positive and negative electrodes. The cracking mode of the current collector with square surface-notch unit of straight edges is similar to that of the flat current collector. Stress concentration sites are evident from the beginning of indentation, scattered in an expanding circular band (Fig.8c). Since the stress in 
circumferential notches does not exceed the ultimate strength of aluminum, the radial cracks do not bifurcate. The square surace-notch unit with double-curved edges leads to a different cracking behavior. The degree of stress concentration along circumferential notches is much higher, eventually causing the formation of the complete circumferential crack when the indentation displacement is $2 \mathrm{~mm}$ (Fig.8d), which qualitatively agrees with the experimental observation in Fig.4e.

(a)
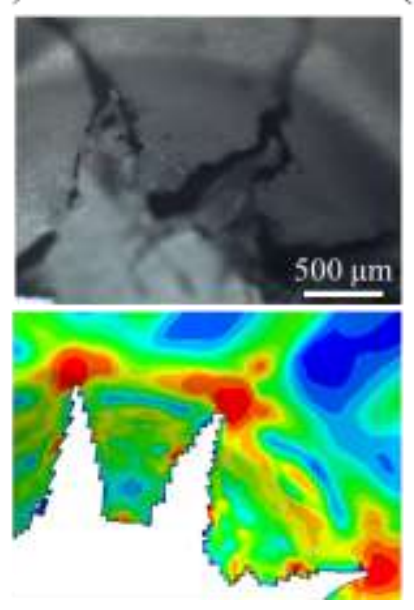

(b)

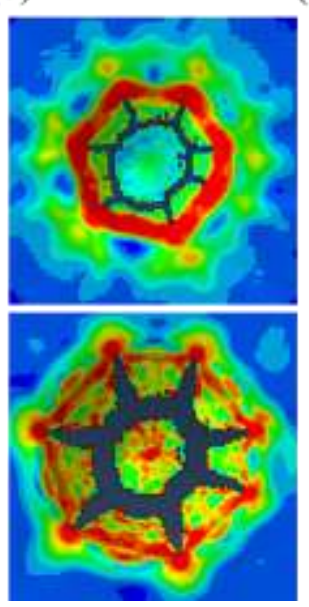

(c)

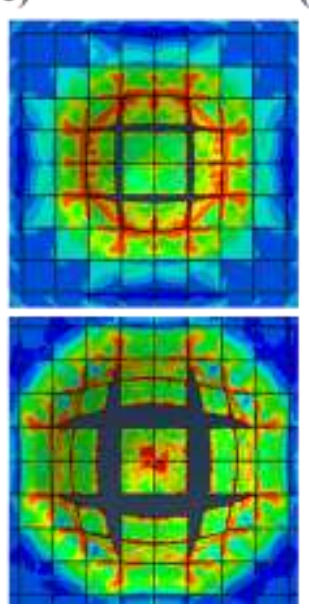

(d)

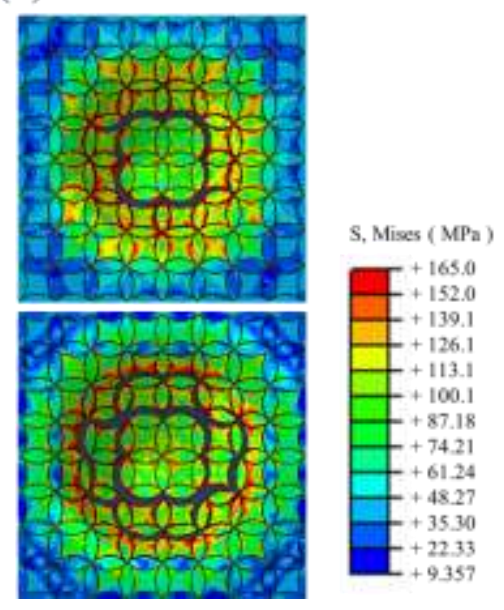

Fig.8 (a) Fracture mode of flat current collector: the experimental observation (top) and the numerical simulation result (bottom). Stress distribution when the indentation displacement is $1 \mathrm{~mm}$ (top) or $2 \mathrm{~mm}$ (bottom): (b) reference flat current collector and modified current collectors with square surface-notch units of (c) straight edges and (d) double-curved edges.

\section{Conclusion}

To summarize, upon external loading, heat generation of a damaged lithium-ion battery (LIB) cell is heavily dependent on the failure mode of the current collector. Flat current collector typically undergoes radial cracking, which causes aggressive internal shorting and fast temperature increase. By creating appropriate surface notches in current collector, the cracking mode can be favorably modified, so as to form circumferential cracks. Complete separation of the damaged electrode area from the far field results in a much reduced heat generation rate. The pattern, edge curvature, and density of surface notches 
are critical factors to the crack nucleation and propagation. Among all the surface-notch designs under investigation, square unit with double-curved edges is most efficient. It leads to negligible temperature increase associated with internal shorting. This technique has important relevance to thermal-runaway mitigation of large-sized high-energy LIB systems. 


\section{Acknowledgement}

This research was supported by the Advanced Research Projects Agency-Energy (ARPA-E) under Grant No. DE-AR0000396, for which we are grateful to Dr. Ping Liu, Dr. John Lemmon, Dr. Grigorii Soloveichik, Dr. Chris Atkinson, and Dr. Dawson Cagle. Special thanks are also due to Dr. Jiang Fan, Dr.

Dengguo Wu, Dr. Hyojung Yoon, and Mr. Minghao Zhang for their help with battery electrode and cell processing. 


\section{Reference}

[1] A. Yoshino, Angew Chem Int Edit, 51 (2012) 5798-5800.

[2] B. Dunn, H. Kamath, J.M. Tarascon, Science, 334 (2011) 928-935.

[3] Y. Idota, T. Kubota, A. Matsufuji, Y. Maekawa, T. Miyasaka, Science, 276 (1997) 1395-1397.

[4] L. Taberna, S. Mitra, P. Poizot, P. Simon, J.M. Tarascon, Nat Mater, 5 (2006) 567-573.

[5] E. Yoo, J. Kim, E. Hosono, H. Zhou, T. Kudo, I. Honma, Nano Lett, 8 (2008) 2277-2282.

[6] L.F. Cui, Y. Yang, C.M. Hsu, Y. Cui, Nano Lett, 9 (2009) 3370-3374.

[7] J.M. Tarascon, M. Armand, Nature, 414 (2001) 359-367.

[8] L. Lu, X. Han, J. Li, J. Hua, M. Ouyang, J Power Sources, 226 (2013) 272-288.

[9] C.J. Lan, J. Xu, Y. Qiao, Y.B. Ma, Appl Therm Eng, 101 (2016) 284-292.

[10] S. Al Hallaj, H. Maleki, J.S. Hong, J.R. Selman, J Power Sources, 83 (1999) 1-8.

[11] W. Zhao, G. Luo, C.Y. Wang, J Electrochem Soc, 162 (2015) A207-A217.

[12] G. Kim, in, National Renewable Energy Laboratory (NREL), Golden, CO., 2011.

[13] R. Zhao, J. Liu, J. Gu, Appl Energy, 173 (2016) 29-39.

[14] W. Zhao, G. Luo, C.Y. Wang, J Electrochem Soc, 162 (2015) A1352-A1364.

[15] X.N. Feng, C.H. Weng, M.G. Ouyang, J. Sun, Appl Energ, 161 (2016) 168-180.

[16] A. Hammami, N. Raymond, M. Armand, Nature, 424 (2003) 635-636.

[17] S. Yayathi, W. Walker, D. Doughty, H. Ardebili, J Power Sources, 329 (2016) 197-206.

[18] Q.S. Wang, P. Ping, X.J. Zhao, G.Q. Chu, J.H. Sun, C.H. Chen, J Power Sources, 208 (2012) 210224.

[19] D.H. Doughty, E.P. Roth, Electrochem Soc Interface, 21 (2012) 37-44.

[20] E. Roth, D. Doughty, D. Pile, J Power Sources, 174 (2007) 579-583.

[21] S.S. Zhang, J Power Sources, 164 (2007) 351-364.

[22] X.S. Huang, J Solid State Electr, 15 (2011) 649-662.

[23] B.A. Johnson, R.E. White, J Power Sources, 70 (1998) 48-54. 
[24] X.M. Feng, X.P. Ai, H.X. Yang, Electrochem Commun, 6 (2004) 1021-1024.

[25] L. Xia, S.L. Li, X.P. Ai, H.X. Yang, Y.L. Cao, Energ Environ Sci, 4 (2011) 2845-2848.

[26] G.-H. Kim, A. Pesaran, R. Spotnitz, J Power Sources, 170 (2007) 476-489.

[27] W. Fang, P. Ramadass, Z.J. Zhang, J Power Sources, 248 (2014) 1090-1098.

[28] A.V. Le, M. Wang, Y. Shi, D. Noelle, Y. Qiao, W.Y. Lu, J Appl Phys, 118 (2015).

[29] A.V. Le, M. Wang, Y. Shi, D.J. Noelle, Y. Qiao, J Phys D Appl Phys, 48 (2015).

[30] M. Wang, A.V. Le, Y. Shi, D.J. Noelle, H. Yoon, M. Zhang, Y.S. Meng, Y. Qiao, J Mater Sci Technol, 32 (2016) 1117-1121.

[31] M. Wang, A.V. Le, D.J. Noelle, Y. Shi, H. Yoon, M. Zhang, Y.S. Meng, Y. Qiao, Int J Damage Mech, (2016) 1056789516660176.

[32] X.W. Zhang, E. Sahraei, K. Wang, Sci Rep, 6 (2016).

[33] A. Kumar, S. Kalnaus, S. Simunovic, S. Gorti, S. Allu, J.A. Turner, J Electrochem Soc, 163 (2016) A2494-A2496.

[34] United States Advanced Battery Consortium, Electrochemical Storage System Abuse Test Procedure Manual

[35] J. Jeevarajan, Internal Shorts in Li-Ion Cells-What Does it Take to Cause One that is Catastrophic, NASA (2012)

[36] P. Liu, E. Sherman, A. Jacobsen, J Power Sources, 189 (2009) 646-650.

[37] S. Tariq, K. Ammigan, P. Hurh, R. Schultz, P. Liu, J. Shang, in: Particle Accelerator Conference, 2003. PAC 2003. Proceedings of the, IEEE, (2003) 1452-1454.

[38] MatWeb, Stainless Steel 304, http://www.matweb.com/. (accessed on 17.01.03)

[39] http://www.cometmetals.com/pdf/aluminum_alloy_guide.pdf. (accessed on 17.01.03)

[40] Y. Xia, T. Wierzbicki, E. Sahraei, X. Zhang, J Power Sources, 267 (2014) 78-97.

[41] Y. Shi, M. Zhang, D. Qian, Y.S. Meng, Electrochim Acta, 203 (2016) 154-161.

[42] S. Santhanagopalan, P. Ramadass, J.Z. Zhang, J Power Sources, 194 (2009) 550-557.

[43] W. Goldsmith, S. Finnegan, Int J Impact Eng, 4 (1986) 83-105. 
[44] Y.-W. Lee, T. Wierzbicki, Int J Impact Eng, 31 (2005) 1277-1308.

[45] D. Clements, N. Widana, Mathematical and computer modelling, 37 (2003) 689-694

[46] B. Landkof, W. Goldsmith, International Journal of Solids and Structures, 21 (1985) 245-266.

[47] G.G. Corbett, S.R. Reid, W. Johnson, Int J Impact Eng, 18 (1996) 141-230.

[48] R. Vermorel, N. Vandenberghe, E. Villermaux, Phys Rev Lett, 104 (2010).

[49] T. Kundu, Fundamentals of fracture mechanics, CRC press, 2008. 

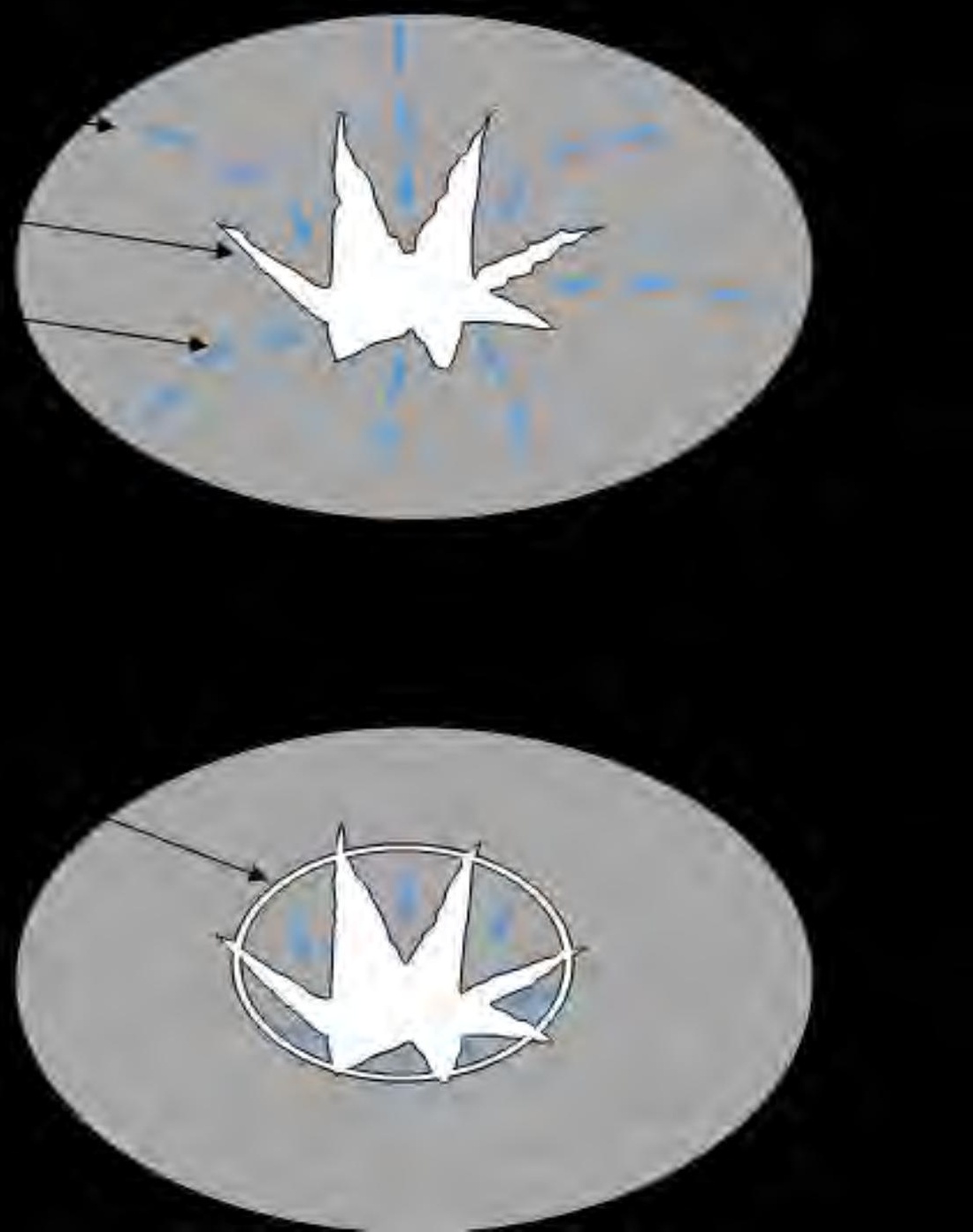